\title{
Nurse's Spiritual Care Competencies to Patient with End Stage Breast Cancer
}

\author{
Nurul Rezki Anisa1, Kadek Ayu Erika ${ }^{2}$, Rini Rachmawaty ${ }^{3}$ \\ ${ }^{1}$ Nursing Medical Surgery, Hasanuddin University, Indonesia \\ ${ }^{2,3}$ Nursing Faculty, Hasanuddin University, Indonesia
}

\section{Article Info \\ Article history: \\ Received Jul 30, 2018 \\ Revised Nov 1, 2018 \\ Accepted Nov 11, 2018}

\section{Keyword:}

Breast cancer

Nurses competencies

Spiritual care

\begin{abstract}
Cancer has many side effects on patient's physic and mostly on mental which may affect on their quality of life. Physically most patients feel fatigue, insomnia, anorexia, nausea, and vomit while mentally they feel emotional disturbances such as anxiety, stress, or depression. One of the methods to that appropriate to overcome both of the conditions is spiritual care. Many research found that because spiritual care associated with better wellbeing, less emotional disturbance, less substance abuse, greater social support, better health behaviours, so it has impact to longer survival periods. This research aimed to investigate nurse's spiritual care competencies to patients with end stage cancer. This was descriptive study design employed Spiritual Care Competencies Scale (SCCS) instrument. A total sampling of 24 nurses working in Oncology department in Dr. Wahidin Sudirohusodo Hospital were recruited. This research found that there are 12 nurses $(50 \%)$ that work in oncology department have low competencies of spiritual care. Involving spiritual care is associated with better wellbeing and longer survival periods. Therefore, it is necessary to increase the competence of nurses on spiritual care in meeting the spiritual needs of patients with end stage breast cancer. A training of spiritual care can be an alternative for nurses to improve spiritual care in hospitals.
\end{abstract}

Copyright $\odot 2018$ Institute of Advanced Engineering and Science. All rights reserved.

\section{Corresponding Author:}

Nurul Rezki Anisa,

Nursing Medical Surgery,

Hasanuddin University, Indonesia.

Email: renisa.cok@gmail.com

\section{INTRODUCTION}

Cancer is a terminal disease that is one of the biggest causes of death every year [1], [2]. Based on estimates from the World Health Organization, cancer causes more deaths than any coronary heart disease or stroke. Breast cancer is a cancer with the highest percentage of new cases after controlling by age, which is $43.3 \%$, and the percentage of death after controlled by age of $12.9 \%$ [2]. Breast cancer is the second highest cancer in Indonesia after cervical cancer and South Sulawesi is ranked fourth of 34 provinces with the highest number of breast cancer patients in Indonesia [3]. Often, breast cancers are found incidentally and are at an advanced stage in the hospital due to the unhealthy symptoms felt in the early stages [4]. New patients do checks at the hospital when symptoms begin to be felt. The reaction of patients with advanced breast cancer diagnostics will experience more psychological stress.

It is known that breast cancer has a poor complication and prognosis in the course of the disease, plus negative side effects on the physical function and quality of life of patients from chemotherapy treatment that patients [5], [6]. Breast cancer and its treatment have physical effects such as fatigue, insomnia, loss of appetite, nausea, vomiting, appearance changes, emotions such as anxiety and depression, and social pressures resulting in decreased body function, sexuality problems, self-image changes, decreased confidence, emotions, severity of physical and psychological function changes [7], [8], [9], [10]. 
Dr. Wahidin Sudirohusodo hospital is one of hospitals that apply palliative care to the terminal patient in Indonesia and spirituality is part of palliative care. Breast cancer is the most prevalence in Dr. Wahidin Sudirohusodo hospital. Based on direct interviews on three breast cancer patients in Dr. Wahidin Sudirohusodo in January 2018, physical and psychosocial complaints during the first year of being diagnosed and undergoing breast cancer treatment include anxiety, stress, depression, fatigue, nausea and vomiting, decreased sexual function, decreased quality of life, even aggressive life-threatening behaviors. Patients emphasize more complaints in psychology and feel it is important to be treated promptly in order to accept the condition of the illness and perform the treatment as directed by the doctor. The patient's fear of therapeutic side effects, comprehensive breast lifting suggestions, and inability to access health facilities affect patient acceptance of the disease. One of the methods that appropriate to overcome both of the conditions is spiritual care [11].

Spiritual needs are an important part of life to find meaning and purpose in life, and increase hope in life [12]. According to the National Consensus Project [13], spiritual care has become part of the national service quality guidelines for terminal illnesses (palliative) and is in domain 5 (spiritual, religious, and maintenance aspects) including advanced cancer that recognizes the religious and spiritual worries of patients and families. The activities of spiritual support include prayer therapy, accompanying the patient by showing support, caring, and empathy, therapeutic communication and listening to many patients, and referring patients to appropriate religious leaders [14].

Nurses in Oncology Department are important to provide spiritual care for near the end of life conditions to find ways to be present in crisis situations of life-threatening patients [15]. Spiritual care is one of the treatment management strategies towards the end of life in the hospital within the Nursing Intervention Classification. Although the patients with end-stage breast cancer told that it become important, there is no data that showed nurses spiritual care competencies at oncology department in Dr. Wahidin Sudirohusodo hospital. Therefore it takes research to investigate the competence of nurse's spiritual care in patients with advanced breast cancer.

\section{RESEARCH METHOD}

This research was descriptive study design employed Spiritual Care Competencies Scale (SCCS) instrument. This research was conducted in Tumor Unit Care of Lontara 2 Dr. Wahidin Sudirohusodo Hospital in Makassar from June to July 2018.

The population in this study was all nurses in the treatment room of Tumor Unit Care. The sampling technique was total sampling. The sample consisted of 24 nurses. Data collected included demographic data (age, tribes, length of work, education and training experience about cancer care) and spiritual care competence scale using Spiritual Care Competency Scale as shown in Table 1.

This research used Spiritual Care Competency Scale (SCCS). SCCS focuses on the psychometric aspects aimed at assessing the competence of spiritual care. Test of validity used Pearson-product moment with significance of 0.05 . It showed the correlation value from the 27 items was valid $(\geq 0.2)$. It was reliable showed by the Cronbach's Alpha coefficient value of 0,694 for 27 items. SCC was developed based on the profile of nursing competencies for spiritual care by van Leeuwen and Cusveller (2004) by distinguishing three domains of spiritual care namely self-awareness and self-care nurses, spiritual nursing dimensions, and nurse quality and skill assurance. There are 27 statements divided into 6 sections of this scale: the assessment and implementation of spiritual care, the professionalization and improvement of the quality of spiritual care, personal support and patient counseling, attitudes toward the patient's spirituality, and communication as shown in Table 2. The measurements for each statement use the 5-point Likert scale by estimating how the nurse's competency level in spiritual care with answer options that 1=strongly disagree, 2=disagree, $3=$ neutral, 4=agree, and 5=strongly agree. Scores of 27-54 are categorized as having no competence, 55-94 scores are categorized as having low competence, 95-107 are categorized as having moderate competence, and the score of $\geq 108$ has high competence.

The protocol and document of this research were agreed and recommended by Health Research Ethic Commission of Medicine Faculty of Hasanuddin University. The registered number of ethical agreement was 367/H4.8.4.5.31/PP36-KOMETIK/2018. The nurse demographic data obtained were analyzed univariat (frequency distribution). Data consists of age, ethnicity, marital status, education, training, duration of work, and nurses' spiritual care competence scale. Data is presented in terms of numbers and percentages. Bivariate analysis was using Mann-whitney test to know the relation of nurse characteristic with spiritual care competence. 


\section{RESULTS AND DISCUSSION}

Table 1 shows the sample characteristics. The number of nurses in Oncology deartment is 24 nurses who are divided into 4 teams with each team leader. There were more female nurses $(70.8 \%)$ than most male nurses $(29.2 \%)$ including the young adult age group $<45$ years of 22 nurses $(91.7 \%)$. Most of the nurses were 14 nurses from Bugis (58.3\%) and Makassar (6.0\%). More nurses in the tumor surgery room have the last education Nursing Diploma (Amd.Kep.) That is as many as 10 nurses (41.7\%). The most widely followed training during work on oncology department was chemotherapy training $(29.2 \%)$ by 7 nurses, but there were 11 nurses who had never attended training $(45.8 \%)$. There are 4 nurses $(16.7 \%)$ who work> 10 years in tumor surgery and more nurses with $<10$ years of work experience. There are nurses who have a moderate spiritual care competence $(25.0 \%)$ and high $(25.0 \%)$. However, in general more nurses who have low spiritual care competence is half of the number of respondents as many as 12 nurses $(50.0 \%)$. The lowest spiritual care competence is the most in nurses with the latest education of nursing diplomas.

Table 2 shows the six parts of the nurses' care spiritual competence in SCCS. There are incompetent nurses in the assessment and implementation of spiritual care $(16.7 \%)$, professionalization and quality improvement of spiritual care $(8.3 \%)$ and referral $(8.3 \%)$. The data also show that high competence is most prevalent in the attitudes toward the patient's spirituality $(54.2 \%)$ and communication (37.5\%). In the meantime, none of them exhibit high competence in the professionalization and improvement of spiritual care and referral qualities.

Table 1. Characteristics of Respondent

\begin{tabular}{|c|c|c|}
\hline \multirow{2}{*}{ Characteristics } & \multicolumn{2}{|c|}{ Sample } \\
\hline & $n$ & $\%$ \\
\hline \multicolumn{3}{|l|}{ Age } \\
\hline Young Adult (20-45 years old) & 22 & 91.7 \\
\hline Old Adult ( $>45$ years old) & 2 & 8.3 \\
\hline \multicolumn{3}{|l|}{ Tribe } \\
\hline Bugis & 14 & 58.3 \\
\hline Makassar & 6 & 25.0 \\
\hline Mandar & 1 & 4.2 \\
\hline Luwu & 1 & 4.2 \\
\hline Toraja & 2 & 8.3 \\
\hline \multicolumn{3}{|l|}{ Marital Status } \\
\hline Not Married & 13 & 54.2 \\
\hline Married & 11 & 45.8 \\
\hline \multicolumn{3}{|l|}{ Last Education } \\
\hline Diploma (Amd.Kep.) & 10 & 41.7 \\
\hline Bachelor of Nurse (S.Kep.) & 7 & 29.2 \\
\hline Nurse (Ns.) & 7 & 29.2 \\
\hline \multicolumn{3}{|l|}{ Training for Cancer Patient Care } \\
\hline Chemotherapy & 7 & 29.2 \\
\hline Palliative Care & 1 & 4.2 \\
\hline Cancer Wound Care & 5 & 20.8 \\
\hline Nothing & 11 & 45.8 \\
\hline \multicolumn{3}{|c|}{ Length of Work at Tumor and Cancer } \\
\hline Care & 10 & 41.7 \\
\hline$<5$ years & 10 & 41.7 \\
\hline $5-10$ years & 4 & 16.7 \\
\hline$\geq 10$ years & & \\
\hline \multicolumn{3}{|l|}{ Nurses Competencies } \\
\hline Low & 12 & 50.0 \\
\hline Moderate & 6 & 25.0 \\
\hline High & 6 & 25.0 \\
\hline
\end{tabular}

Table 2. Part of Nurse Competence with Spiritual Care Competencies Scale

\begin{tabular}{|c|c|c|c|c|}
\hline & \multicolumn{3}{|c|}{ Spiritual Care Competencies } & \multirow[b]{2}{*}{$\begin{array}{c}\text { High Competencen } \\
(\%)\end{array}$} \\
\hline & $\begin{array}{c}\text { Not } \\
\text { Competentn }(\%)\end{array}$ & $\begin{array}{l}\text { Low Competencen } \\
(\%)\end{array}$ & $\begin{array}{c}\text { Medium } \\
\text { Competencen }(\%)\end{array}$ & \\
\hline $\begin{array}{l}\text { Assessment and implementation of } \\
\text { spiritual care }\end{array}$ & $4(16.7)$ & $7(29.2)$ & $9(37.5)$ & $4(16.7)$ \\
\hline $\begin{array}{l}\text { Professionalization and quality } \\
\text { improvement of spiritual care }\end{array}$ & $2(8.3)$ & $11(45.8)$ & $11(45.8)$ & - \\
\hline Reference & $2(8.3)$ & - & $22(91.7)$ & - \\
\hline $\begin{array}{l}\text { Personal support and patient } \\
\text { counseling }\end{array}$ & - & $2(8.3)$ & $16(66.7)$ & $6(25.0)$ \\
\hline Attitude to patient spirituality & - & - & $11(45.8)$ & $13(54.2)$ \\
\hline Communication & - & - & $15(62.5)$ & $9(37.5)$ \\
\hline
\end{tabular}

IJPHS Vol. 7, No. 4, December 2018: $268-273$ 
Table 3. Crosstab Competence of Nurses' Spiritual Care with Characteristics

\begin{tabular}{|c|c|c|c|c|}
\hline \multicolumn{5}{|c|}{ Spiritual Care Competencies } \\
\hline & $\begin{array}{c}\text { Low Competencen } \\
(\%)\end{array}$ & $\begin{array}{c}\text { Moderate } \\
\text { Competencen }(\%)\end{array}$ & $\begin{array}{c}\text { High } \\
\text { Competencen }(\%)\end{array}$ & $\mathrm{p}$ value \\
\hline \multicolumn{5}{|l|}{ Age } \\
\hline Young Adult & $12(54.5 \%)$ & $4(18.2 \%)$ & $6(27.3 \%)$ & \multirow{2}{*}{0.495} \\
\hline Old Adult & $0(0.0 \%)$ & $2(100.0 \%)$ & $0(0.0 \%)$ & \\
\hline \multicolumn{5}{|l|}{ Gender } \\
\hline Men & $5(71.4 \%)$ & $0(0.0 \%)$ & $2(28.6 \%)$ & \multirow[t]{2}{*}{0.407} \\
\hline Female & $7(41.2 \%)$ & $6(35.3 \%)$ & $4(66.7 \%)$ & \\
\hline \multicolumn{5}{|l|}{ Ethnicity } \\
\hline Bugis & $5(35.7 \%)$ & $3(21.4 \%)$ & $6(42.9 \%)$ & \multirow{5}{*}{0.236} \\
\hline Makassar & $5(83.3 \%)$ & $1(16.7 \%)$ & $0(0.0 \%)$ & \\
\hline Mandar & $1(100.0 \%)$ & $0(0.0 \%)$ & $0(0.0 \%)$ & \\
\hline Luwu & $0(0.0 \%)$ & $1(100.0 \%)$ & $0(0.0 \%)$ & \\
\hline Toraja & $1(50.0 \%)$ & $1(50.0 \%)$ & $0(0.0 \%)$ & \\
\hline \multicolumn{5}{|l|}{ Marital Status } \\
\hline Not Married & $3(61.5 \%)$ & $3(23.1 \%)$ & $2(15.4 \%)$ & \multirow[t]{2}{*}{0.186} \\
\hline Married & $4(36.4 \%)$ & $3(27.3 \%)$ & $4(36.4 \%)$ & \\
\hline \multicolumn{5}{|l|}{ Education } \\
\hline Diploma & $5(50.0 \%)$ & $2(20.0 \%)$ & $3(30.0 \%)$ & \multirow{3}{*}{0.942} \\
\hline Bachelor of Nurse & $3(42.9 \%)$ & $2(28.6 \%)$ & $2(28.6 \%)$ & \\
\hline Ners & $4(57.1 \%)$ & $2(28.6 \%)$ & $1(14.3 \%)$ & \\
\hline \multicolumn{5}{|l|}{ Training } \\
\hline Chemotherapy & $0(0.0 \%)$ & $2(28.6 \%)$ & $5(71.4 \%)$ & \multirow{5}{*}{0.005} \\
\hline Palliative Care & $0(0.0 \%)$ & $1(100.0 \%)$ & $0(0.0 \%)$ & \\
\hline Wound Cancer & $4(80.0 \%)$ & $0(0.0 \%)$ & $1(20.0 \%)$ & \\
\hline Nothing & $8(72.7 \%)$ & $3(27.3 \%)$ & $0(0.0 \%)$ & \\
\hline Total & $12(50.0 \%)$ & $6(25.0 \%)$ & $6(25.0 \%)$ & \\
\hline
\end{tabular}

Based on the SCC scale for measuring nurses' spiritual care competencies, the study found that more nurses had lower competence in the Oncology department of the hospital. There are six parts of spiritual care competence on SCC scale. The scale measures assessment and implementation of spiritual care, professionalization and quality improvement of spiritual care, personal support and patient counseling, referrals, attitudes toward the patient's spirituality, and communication.

The results of this study indicate that the nurses are not competent in the assessment and implementation, professionalization and improvement, and spiritual care referral. These three parts are the main competencies and the implementation of spiritual care in the health services in hospitals. The presence of incompetent nurses in the section indicates a lack of nurse ability in terms of science and competence to provide spiritual care in patients with advanced breast cancer. This is supported by the characteristic data that most nurses do not have previous training experiences. The personal support and counseling, attitudes toward spirituality, and communication to the patient instead show a high degree of competence in surgical nurse tumors. These three parts represent the sense of care and nurses empathy to terminal conditions of patients with advanced breast cancer. This shows that nurses have a high sense of care to provide spiritual care to patients. Therefore, if it is supported by the ability and good basic competence on the assessment, implementation, and professionalization it will form a spiritual service that provides a positive effect in overcoming psychological problems in patients with advanced breast cancer.

Low-competence nurses are nurses who have never had previous training experience. This shows that the role of training has an influence on spiritual care competence. Of the three types of training that have been followed by oncology nurses, it appears that basic chemotherapy training has a positive influence on the competence of spiritual care. It is shown from data that nurses who have attended chemotherapy training have high spiritual care competence. On the contrary it is different from the training of cancer wound care which shows that more nurses have low spiritual care competence. It may only support nurse's skill and not touch the sense of care to provide spiritual care for cancer patients. Therefore, in wound care training should be added with the provision of material on fulfilling the spirituality of cancer patients in terminal conditions.

When cancer becomes part of the journey of life, it will be hard for the patient. Patients diagnosed with advanced cancer will also affect their immediate family. Most patients living with advanced breast cancer live with death threats because of the malignancy of the disease. Many come to the point where cancer no longer responds to uncontrolled treatment and disease progression [16]. The goal of therapy today is the provision of support and reduction of pressure for the patient to arrive at death. Therefore, cancer should be understood not only as a physical illness, but it requires patients and nurses to understand the meaning of life and relationships.

Spiritual care is one of the treatment management strategies toward the end of life in hospital within the Nursing Intervention Classification. Based on a review of existing research, effective spiritual care is 
necessary to overcome psychological problems such as anxiety, stress, or depression and an impact on the acceptance of sickness conditions with the emergence of physical problems or other symptoms of breast cancer treatment effects. Spiritual involvement is associated with better patient wellbeing, less emotional distress, less substance abuse, greater social support, better health behaviors, and longer survival periods.

There are many studies that show the importance of spiritual care in hospitals, as well as the effectiveness of the assessment and handling of spiritual problems on better patient wellbeing. Religious patients tend to have better physical health than non-religious immune function better in more than $50 \%$ of 25 studies; endocrine function is better in almost $75 \%$ of 31 studies; better cardiovascular function approaching $70 \%$ of 16 studies; Coronary heart disease was lacking in nearly two-thirds of 19 studies; lowered blood pressure in nearly $60 \%$ of 63 studies; less cancer or better prognosis in more than half of 25 studies, and overall greater longevity in $68 \%$ of the 121 studies, including more than $75 \%$ of the most rigorously designed studies [17]. Research shows that when spiritual needs are not addressed in medical care, this not only reduces the quality of life and patient satisfaction with care, but also increases two or three times the cost of health care towards the end of life [12], [17], [18], [19].

\section{CONCLUSION}

Spiritual care is the right supportive therapy to provide support and reduce pressure for patients until they reach death. Dr. Wahidin Sudirohusodo as a hospital that runs a palliative care program (palliative care) has facilitated the provision of spiritual care in the treatment room cooperated with clergy. As a place to provide health services for advanced cancer patients, the hospital is expected to provide nurses who are competent for spiritual care to be able to meet the spiritual needs of patients towards the end of life.

Based on a survey of spiritual care nurses' competence in the Lontara 2 of Oncology Deaprtment, it was found that there were half of the nurses working in the room who had low spiritual care competencies. Therefore, it is necessary to increase the competence of nurses to spiritual care in meeting the spiritual needs of patients with advanced breast cancer in hospitals. The existence of training can be an alternative for nurses to improve spiritual care in hospitals.

\section{REFERENCES}

[1] Indonesian Ministry of Health. Glibal situation of cancer disease. Data and Information Bulletin of the Indonesian Ministry of Health. https://doi.org/10.1007/s13398-014-0173-7.2, 2015.

[2] GLOBOCAN. Estimated Incidence, Mortality and Prevalence Worldwide in 2012. Retrieved from http://globocan.iarc.fr/Pages/fact_sheets_cancer.aspx, 2012.

[3] Indonesian Ministry of Health, Riskesdas. Jakarta: Health Research and Development Department of Indonesian Ministry of Health, 2013.

[4] Black, Joyce M., \& Hawks, Jame Hokanson. Medical Surgery of Nursing: Book 1 Clinical Management for the Expected Results. 8th edition. Singapore: Elsevier, 2014.

[5] Olver, I. N., Eliott, J. A., \& Koczwara, B. "A Qualitative Study Investigating Chemotherapy-Induced Nausea as a Symptom Cluster" Support Care Cancer. https://doi.org/10.1007/s00520-014-2276-2, 2014.

[6] Shahriari, M., Dehghan, M., Pahlavanzadeh, S., \& Hazini, A. "Effects of Progressive Muscle Relaxation, Guided Imagery and Deep Diaphragmatic Breathing on Quality of Life in Elderly with Breast or Prostate Cancer" Journal of Education and Health Promotion, 1-6. https://doi.org/10.4103/jehp.jehp, 2017.

[7] Adeola, M. T., Baird, C. L., Sands, L. P., Longoria, N., Henry, U., Nielsen, J., \& Shields, C. G. “Active Despite Pain: Patient Experiences With Guided Imagery With Relaxation Compared To Planned Rest," Clinical Journal of Oncology Nursing, 19(6), 649-652, 2015.

[8] Donovan, K. A., Thompson, L. M. ., \& Jacobsen, P. B., Handbook of Pain and Palliative Care Biobehavioral Approaches for the Life Course: Pain, Depression, And Anxiety In Cancer. (R. J. Moore, Ed.). London: Springer Science+Business Media. https://doi.org/10.1007/978-1-4419-1651-8, 2012.

[9] Kim, I., Cho, J., Choi, E., Kwon, I. G., Hee, Y., Lee, J. E., Yang, J. "Perception, Attitudes, Preparedness and Experience of Chemotherapy-Induced Alopecia among Breast Cancer Patients: a Qualitative Study" Asian Pacific Journal of Cancer Prevention, 13, 1383-1388, 2012.

[10] Zainal, N. Z., Nik-jaafar, N. R., Baharudin, A., Sabki, A., \& Guan Ng, C. "Prevalence of Depression in Breast Cancer Survivors : a Systematic Review of Observational Studies" Asian Pacific Journal of Cancer Prevention, 14, 2649-2656, 2013.

[11] Baldacchino, D. Spiritual care education of health care professionals. Religions, 594-613, 2015.

[12] Jafari, N., Zamani, A., \& Farajzadegan, Z. "The Effect of Spiritual Therapy for Improving the Quality of Life of Women with Breast Cancer: A Randomized Controlled Trial," 37-41, October, 2013.

[13] National Concensus Project. Clinical Practice Guidelines Palliative Care (3rd ed.). United States of America: National Consensus Project for Quality Palliative Care, 2013.

[14] Bulechek, Gloria M., Butcher, Howard K., Dochterman, Joanne M., Wagner, Cheryl M. Nurisng Intervention Classification (NIC). 6th edition. Elsevier: Oxford, 2013. 
[15] Sansó, N., Galiana, L., Oliver, A., Pascual, A., Sinclair, S., \& Benito, E. "Palliative Care Professionals' Inner Life: The Relationshipsamong Awareness, Self-Care and Compassion Satisfaction and Fatigue, Burn Out, and Coping with Death" Journal Pain and Symptom Management, http://doi.org/10.1016/j.jpainsymman.2015.02.013, 2 April 2015.

[16] Black, Joyce M., \& Hawks, Jame Hokanson. "Medical Surgery of Nursing: Book 1 Clinical Management for the Expected Results" 8th edition. Singapore: Elsevier, 2014.

[17] Balboni, M. J., Sullivan, A., Amobi, A., Phelps, A. C., Gorman, D. P., Zollfrank, A., Balboni, T. A. "Why is Spiritual Care Infrequent at the end of Life? Spiritual Care Perceptions among Patients, Nurses, and Physicians and the Role of Training" Journal of Clinical Oncology, 31(4), 461-467. https://doi.org/10.1200/JCO.2012.44.6443, 2013.

[18] Balboni, T. A., Balboni, M., Enzinger, A. C., Gallivan, K., Paulk, M. E., Wright, A., Prigerson, H. G. "Provision of Spiritual Support to Patients With Advanced Cancer by Religious Communities and Associations with Medical Care at the End of Life" JAMA Intern Med, 173(12), 1109-1117. https://doi.org/10.1001/jamainternmed.2013.903, 2013.

[19] Vilalta, A., Valls, J., Porta, J., \& Viñas, J. "Evaluation of Spiritual Needs of Patients with Advanced Cancer in a Palliative Care Unit" Journal of Palliative Medicine, 17(5), 2014. 